\title{
Secretory immunoglobulin A from human milk hydrolyzes microRNA
}

\author{
Ivan Y. Kompaneets, Evgeny A. Ermakov, ๑ Sergey E. Sedykh, ๑ Valentina N. Buneva, (1) \\ and Georgy A. Nevinsky* (D) \\ Institute of Chemical Biology and Fundamental Medicine, SD of Russian Academy of Sciences, 8 Lavrentiev Ave., Novosibirsk 630090, Russia
}

\begin{abstract}
For breast-fed infants, human milk is a source of various nutrients (e.g., proteins, peptides, antibodies) and bioactive components that promote neonatal growth and protect infants from viral and bacterial infection. Moreover, in terms of infant nutrition and protection the functions of many human milk components are very different from those of blood and other biological fluids of healthy adults. For example, catalytic antibodies ("abzymes") with synthetic activities (protein, oligosaccharide, and lipid kinase activities) have been found in human breast milk that are absent in the blood of healthy people. Abzymes with hydrolyzing functions have been detected not only in milk, but also in the blood of patients with autoimmune diseases. Obviously, feeding newborns human milk has a very specific role and it is a unique aspect of mammalian nutrition. Ribonuclease and DNase autoantibodies or abzymes are found in milk and blood of lactating women, but not in blood sera of healthy men and nonpregnant woman. Here, we present the first evidence that human milk secretory IgA molecules (sIgA) can effectively hydrolyze ribooligonucleotides containing 23 different bases $\left[(\mathrm{pN})_{23}\right.$ ribooligonucleotides] and 4 microRNAs: miR9-5p, miR-219-2-3p, miR-137, and miR-219a-5p. Ribonuclease activity is an inherent property of sIgAs. We showed that 7 individual sIgAs hydrolyzed the ribooligonucleotides $(\mathrm{pA})_{23},(\mathrm{pU})_{23}$, and $(\mathrm{pC})_{23}$ nonspecifically and with comparable efficiency, whereas hydrolysis of the 4 microRNAs by sIgAs was site-specific. Sites of hydrolysis of 4 microRNAs by IgG from blood of patients with schizophrenia have been previously identified. The sites of hydrolysis of 4 microRNAs by sIgA-abzymes were very different from the previously identified sites of hydrolysis by $\operatorname{IgG}$ in patients with schizophrenia. In
\end{abstract}

Received October 31, 2019.

Accepted March 31, 2020.

*Corresponding author: nevinsky@niboch.nsc.ru addition, in contrast to IgG, milk sIgAs efficiently hydrolyzed microRNAs in their loop and duplex regions. Key words: human milk, abzyme, microRNA hydrolysis

\section{INTRODUCTION}

Antibodies (Abs) against stable analogs of transition states of chemical reactions with catalytic activities are called "abzymes" and are well described in the literature (for reviews, see Nevinsky and Buneva, 2003, 2005; Keinan, 2005; Nevinsky, 2010, 2011, 2016, 2017). The blood of patients with different autoimmune diseases can contain various auto-Abs directly to antigens mimicking transition states of chemical reactions or secondary anti-idiotypic Abs to active sites of enzymes (Nevinsky and Buneva, 2003, 2005; Keinan, 2005; Nevinsky, 2010, 2011, 2016, 2017). The existence of abzymes in the blood is a clear sign of autoimmune processes occurring in the human body (Nevinsky and Buneva, 2003, 2005; Keinan, 2005; Nevinsky, 2010, 2011, 2016, 2017). To date, IgG, IgA, and IgM molecules that hydrolyze DNA, RNA, polysaccharides, oligopeptides, and proteins have been found in the blood of patients with various autoimmune and some viral diseases (for a review, see Nevinsky and Buneva, 2003, 2005; Keinan, 2005; Nevinsky, 2010, 2011, 2016, 2017).

Human milk contains IgG, IgM, IgA, and secretory $\operatorname{Ig} \mathrm{A}(\mathbf{s I g} \mathbf{A})$, of which $\operatorname{sIg} \mathrm{A}$ is the major component (>85-90\%; Mestecky et al., 1986; Hanson et al., 1994). Immunoglobulin A molecules are produced by B lymphocytes of the local immune system in the mammary gland (Hanson et al., 1994) and they are represented in maternal Peyer's patch lymphoid cells; IgA migrate to mucosal sites and generate local sIgA antibody responses. During the first 5 to 6 mo of life, the immune system of newborns is not fully operational: the mucous surfaces of the respiratory and gastroenterological tracts of infants lack antibodies (Hanson et al., 1979). Secretory IgAs in breast milk remain high for at least 7.5 mo after birth and play an important role in maintaining the passive humoral response (Rechtman et al., 2002). 
It has been shown that small subfractions of human milk polyclonal IgGs and sIgAs hydrolyze DNA, RNA (Buneva et al., 1998, 2003), ribo- and deoxyribo mono-, di-, and triphosphates (NMP, NDP, and NTP), remove 5'-terminal phosphates of DNA and RNA (i.e., phosphatase activity; Semenov et al., 2004), and hydrolyze polysaccharides (Savel'ev et al., 2001) and proteins (Odintsova et al., 2005). Breast milk contains sIgAs in very high concentrations, and sIgAs demonstrate higher enzymatic activity than milk IgGs. Therefore, analysis of sIgAs is of particular interest because they play the most important role in the biological functions of milk.

Interestingly, during pregnancy and immediately after birth, women demonstrate a sharp exacerbation of reactions similar to autoimmune processes in the case of typical autoimmune diseases such as systemic lupus erythematosus (SLE), multiple sclerosis, antiphospholipid syndrome, thyroiditis, and renal insufficiency, among others (Freeman et al., 1986; Hazes, 1991; Dayan and Daniels, 1996; Amino et al., 1999; Tanaka et al., 2000; Nevinsky and Buneva, 2003, 2005; Keinan, 2005; Nevinsky, 2010, 2011, 2016, 2017). Pregnant women may be immunized by different compounds of bacterial, viral, or food origin, which can effectively stimulate production of different $\mathrm{Abs}$ and abzymes (Buneva et al., 1998, 2003; Nevinsky and Buneva, 2003, 2005; Keinan, 2005; Nevinsky, 2010, 2011, 2016, 2017). During pregnancy and lactation, the blood of women contains fetal cells in small concentrations (Kazakov et al., 1995) and DNA in elevated concentrations similar to blood of patients with autoimmune diseases including SLE and multiple sclerosis. Thus, many different autoimmune diseases can be "activated" or "triggered" in healthy women during pregnancy and soon after childbirth (Freeman et al., 1986; Hazes, 1991; Dayan and Daniels, 1996; Buneva et al., 1998, 2003; Amino et al., 1999; Nevinsky et al., 2000; Tanaka et al., 2000; Savel'ev et al., 2001; Semenov et al., 2004). Pregnancy and especially the beginning of lactation are important periods associated with the production not only of different Abs, but also of abzymes, which indicate the development of autoimmune reactions (Nevinsky and Buneva, 2003, 2005; Keinan, 2005; Nevinsky, 2010, 2011, 2016, 2017).

It has been shown that autoimmune diseases originate from defects or changes in hematopoietic stem cells (Watanabe-Fukunaga et al., 1992; Andryushkova et al., 2006, 2007, 2009; Doronin et al., 2016; Aulova et al., 2017). However, these changes are very similar in typical autoimmune diseases and healthy lactating mice (Nevinsky and Buneva, 2003, 2005; Keinan, 2005; Andryushkova et al., 2006, 2007, 2009; Nevinsky, 2010,
2011, 2016, 2017). Immediately after the beginning of lactation (4-14 d after delivery), significant changes are observed in differentiation profiles of the hematopoietic stem cells in healthy lactating mice, comparable to those for mice demonstrating deep SLE pathology (Andryushkova et al., 2006, 2007, 2009). In addition, changes in the profile of differentiation of hematopoietic stem cells in lactating mice were shown to be temporary, returning to baseline 1 to 2 mo after birth, whereas they were permanent in mice with spontaneously developed SLE (Andryushkova et al., 2006, 2007, 2009).

Abzymes with low catalytic activity appear in the blood of women mainly in the third trimester of pregnancy (Buneva et al., 2003). The dynamics of the increase in the concentration of abzymes with DNase activity correlates with the dynamics of the increase in the blood concentration of DNA and the level of cell apoptosis. From our point of view, the peculiarity of the reorganization of the immune system of a pregnant woman is the switching-on of a special "immune memory," which accumulates, during pregnancy, all information about harmful environmental factors (Nevinsky and Buneva, 2003, 2005; Keinan, 2005; Andryushkova et al., 2006, 2007, 2009; Nevinsky, 2010, 2011, 2016, 2017). This information is partially used by the immune system during pregnancy, but mostly immediately after the onset of lactation (Buneva et al., 1998, 2003; Nevinsky et al., 2000; Savel'ev et al., 2001; Semenov et al., 2004).

Most abzymes catalyze the hydrolysis of various substrates. The first examples of abzymes catalyzing synthesis were sIgAs from the human milk that could phosphorylate 15 milk proteins (Nevinsky et al., 1998; Kit et al., 1996), unique lipids (Gorbunov et al., 2000, 2005), and polysaccharides (Karataeva et al., 2006a,b). In general, the immune system of pregnant and lactating women is very different from that of other healthy people.

Noncoding short microRNAs (miRNA; $18-25 \mathrm{nu}-$ cleotides) are present, both intra- and extracellularly, in different body fluids of humans and animals (Ferro et al., 2019; Matsuyama and Suzuki, 2019). They can have very different biological functions, including regulation of genes (Miller and Wahlestedt, 2010; Melnik and Schmitz, 2017). Different changes in miRNAs of a large number of different cell types (miRNA-regulated gene network) can lead to alteration in the expression of many genes. Human milk contains from several tens to thousands of different miRNAs (Alsaweed et al., 2015a,b, 2016a,b,c; Golan-Gerstl et al., 2017; Melnik and Schmitz, 2017). Human milk miRNAs have poten- 
tially important functions for both the lactating breast and the infants (Alsaweed et al., 2015a).

Considering the important role of miRNAs in proliferation, differentiation, and maturation of cells, we were interested in analyzing the potential production of specific abzymes against any miRNAs. In the present work, we performed a quantitative analysis of hydrolysis of miRNAs by sIgA antibodies isolated from milk. In addition, we analyzed the substrate specificity of milk abzymes in the hydrolysis of human milk microRNAs.

\section{MATERIALS AND METHODS}

\section{Chemicals and Donors}

Most chemicals used for this study were purchased from Sigma (St. Louis, MO). Superdex 200 HR 10/30 column, Protein G-Sepharose, and Protein A-Sepharose were obtained from GE Healthcare (GE Healthcare, New York, NY). Fluorescein isothiocyanate (FITC) was purchased from Thermo Fisher Scientific (Waltham, MA). The FITC conjugates of oligonucleotides were synthesized using a solid-phase phosphoramidite method as described by Chernikov et al. (2017). All ribooligonucleotides were homogeneous, as demonstrated by ion-exchange and reversed-phase chromatography and electrophoresis in $20 \%$ polyacrylamide gel. RNase A and FastAP thermosensitive alkaline phosphatase were from Fisher Scientific (Pittsburgh, PA).

The local human ethics committee of Novosibirsk State Medical University (Novosibirsk, Russia) specifically approved this study, and the milk sampling protocol, in conformity with Declaration of Helsinki ethics committee guidelines. All mothers gave written consent and donated their milk for scientific purposes. The mothers had no history of respiratory, autoimmune, gastrointestinal, rheumatologic, cardiovascular, or other system pathologies.

\section{Purification and Analysis of Antibodies}

Antibodies were purified individually from each milk sample similar to previously published methods (Kit et al., 1996; Nevinsky et al., 1998; Gorbunov et al., 2000, 2005; Karataeva et al., 2006a,b). The milk (100 $\mathrm{mL}$ at one time) of 7 clinically healthy females living in the Novosibirsk region of Russia (19-35 yr old) was collected 1 to 4 wk after the beginning of the lactation using standard sterile devices. Within 1 to $3 \mathrm{~h}$ after milk collection, samples cooled to $4^{\circ} \mathrm{C}$ were centrifuged for $20 \mathrm{~min}$ at room temperature and $16,500 \times g$ using an Eppendorf centrifuge (Eppendorf, Hamburg, Germany); cells and the lipid phase were removed to obtain milk plasma. All determined parameters (relative content of Abs and their enzymatic activities) were the same during 4 wk of lactation (Nevinsky and Buneva, 2003, 2005; Keinan, 2005; Nevinsky, 2010, 2011, 2016, 2017).

The obtained plasma was loaded on a Protein GSepharose column equilibrated with buffer A $(20 \mathrm{mM}$ Tris- $\mathrm{HCl}$ buffer, $\mathrm{pH} 7.5 ; 0.15 \mathrm{M} \mathrm{NaCl}$ ) to remove IgG. The flow-through fraction containing SIgA was applied to a Protein A-Sepharose column equilibrated with the same buffer A. All nonspecifically adsorbed proteins were eluted from the Protein A-Sepharose column first with buffer A to zero optical density, and then with buffer A containing $0.3 \mathrm{M} \mathrm{NaCl}$ and $1 \%$ Triton X-100, and again with buffer A. The sIgAs were specifically eluted from the sorbents with $0.1 \mathrm{M}$ glycine- $\mathrm{HCl}(\mathrm{pH}$ 2.6), immediately neutralized using $1 M$ Tris- $\mathrm{HCl}(\mathrm{pH}$ 8.5), and dialyzed against $20 \mathrm{~m} M$ Tris- $\mathrm{HCl}(\mathrm{pH} 7.5)$.

For additional purification, sIgA preparations (1-5 $\mathrm{mg} / \mathrm{mL}, 0.3 \mathrm{~mL}$ ) were incubated in $20 \mathrm{mM}$ acidic glycine-HCl buffer ( $\mathrm{pH} 2.6$ ) containing $0.2 \mathrm{M} \mathrm{NaCl}$ at $25^{\circ} \mathrm{C}$ for 20 to $30 \mathrm{~min}$ and then additionally purified by fast protein liquid chromatography (FPLC) gel filtration on Superdex 200 HR 10/30 as previously reported (Kit et al., 1996; Nevinsky et al., 1998; Gorbunov et al., 2000, 2005; Karataeva et al., 2006a,b). Collected fractions were immediately neutralized using Tris- $\mathrm{HCl}(\mathrm{pH} 9.0)$, and dialyzed against $20 \mathrm{mM}$ Tris- $\mathrm{HCl}(\mathrm{pH}$ 7.5). To permit refolding of antibodies after acidic treatment, RNase activity of Abs was measured after 1 to 2 wk of storage in this buffer at $4^{\circ} \mathrm{C}$.

\section{Analysis of MiRNA Hydrolysis by Abs}

Labeled ribooligonucleotides containing $23 \mathrm{~A}, \mathrm{C}$, or U bases [5'-Flu- $\left.(\mathrm{pA})_{23}, 5^{\prime}-\mathrm{Flu}-(\mathrm{pC})_{23}, 5^{\prime}-\mathrm{Flu}-(\mathrm{pU})_{23}\right]$, miR137 (5'-Flu-UUAUUGCUUAAGAAUACGCGUAG), miR-9-5p (5'-Flu-UCUUUGGUUAUCUAGCUGUAUGA), miR-219-2-3p (5'-Flu-AGAAUUGUGGCUGGACAUCUGU), and miR-219a-5p (5'-Flu-UGAUUGUCCAAACGCAAUUCU) contained a fluorescent residue (fluorescein, Flu) on their 5'-termini. These microRNAs were selected because they are the most commonly reported in human milk (Alsaweed et al., 2015a, 2016c; Melnik and Schmitz, 2017).

Analysis of RNA hydrolysis was done as previously described (Ermakov et al., 2018a,b). The reaction mixture $(10 \mu \mathrm{L})$ contained $50 \mathrm{~m} M$ Tris- $\mathrm{HCl}(\mathrm{pH} 7.5)$; $0.01 \mathrm{mg} / \mathrm{mL}$ of one labeled ribooligonucleotide $(\mathbf{O N})$ or miRNA and $40 \mu \mathrm{g} / \mathrm{mL}$ sIgA. The mixtures were in- 
cubated for $1 \mathrm{~h}$ at $37^{\circ} \mathrm{C}$, and the reaction was stopped by addition of a denaturing buffer $(10 \mu \mathrm{L})$ containing $8 M$ urea and $0.025 \%$ xylene cyanol. The products of RNA hydrolysis were analyzed by $20 \%$ PAGE using denaturing conditions $[0.1 M$ boric acid, $0.1 M$ Tris, $8 M$ urea, and $0.02 M \mathrm{Na}_{2}$ EDTA (pH 8.3)]. All gels were analyzed using Typhoon FLA 9500 laser scanner (GE Healthcare, New York, NY). To obtain markers of oligonucleotide length (number of mononucleotides in oligonucleotides), limited statistical hydrolysis (approximately the same non-specific hydrolysis efficiency at all internucleotide bonds) of ON and microRNA with unspecific alkaline ribonuclease (hydrolyzing such substrates with approximately the same efficiency at all internucleoside bonds) and specific RNase T1 hydrolysis was used. Products after alkaline hydrolysis containing cyclic 3'-monophosphate have lower electrophoretic mobility and give additional bands. Therefore, they were treated with FastAP thermally sensitive alkaline phosphatase (Fisher Scientific). All gels were analyzed using Typhoon FLA 9500 laser scanner (GE Healthcare). The results are reported as mean \pm standard deviation of at least 3 independent experiments.

\section{In Situ RNase Activity Assay}

Sodium dodecyl sulfate-PAGE analysis of Abs (central part of the sIgA peak after gel filtration) for homogeneity under nonreducing conditions was performed in a 4 to $18 \%$ gradient gel containing $0.1 \%$ SDS (Laemmli system), and that for the polypeptide spectrum was performed in a $12 \%$ reducing gel containing $0.1 \%$ SDS and $50 \mathrm{~m} M$ dithiothreitol according to Nevinsky et al. (1998), Kit et al. (1996), Gorbunov et al. (2000, 2005), and Karataeva et al. (2006a,b).

The in situ analysis of RNase activity of an equimolar mixture of 7 individual preparations $\left(\mathbf{s} \mathbf{I g} \mathbf{A}_{\text {mix }} ; 10\right.$ $\mu \mathrm{g}$;) was carried out in 4 to $18 \%$ SDS-PAGE containing $40 \mu \mathrm{g} / \mathrm{mL}$ polymeric yeast RNA in the mixture before copolymerization, as previously reported (Kit et al., 1996; Nevinsky et al., 1998; Gorbunov et al., 2000, 2005; Karataeva et al., 2006a,b). Before electrophoresis, the $\operatorname{sIg} \mathrm{A}_{\text {mix }}$ was incubated at $20^{\circ} \mathrm{C}$ for 10 to 20 min in $20 \mathrm{~m} M$ Tris-HCl (pH 7.5) containing 0.1\% SDS. After electrophoresis, the gel was washed for 1 to $2 \mathrm{~h}$ to remove SDS using 0.1\% Triton X-100 in $20 \mathrm{~m} M$ Tris$\mathrm{HCl}, \mathrm{pH} 7.5$, followed by washing several times with the same buffer, and finally with $20 \mathrm{~m} M$ Tris- $\mathrm{HCl}$. The gel was then incubated in reaction buffer $(40 \mathrm{~m} M$ Tris- $\mathrm{HCl}$, $\mathrm{pH} 7.5$ ) for $48 \mathrm{~h}$ at $37^{\circ} \mathrm{C}$. The gel was cut into 2 halves, one of which was stained with ethidium bromide, and the stained gels were photographed and imaged using
Molecular Imager PharosFX Plus System (Bio-Rad Laboratories, Hercules, CA). The fragments of the gel in which the RNA cleavage occurred were detected as dark spots on a uniformly fluorescent background. The other half of the gel was stained with Coomassie R-250, and the position of sIgAs bands was identified.

\section{Spatial Model of MiRNAs}

The spatial models of 4 miRNAs were generated previously by the Predict a Secondary Structure server (http://rna.urmc.rochester.edu/RNAstructureWeb/ Servers/Predict1/Predict1.html), which uses a combination of 4 algorithms to predict the secondary structure of RNA (Ermakov et al., 2018a,b), calculating a partition function and predicting the structure with minimal energy.

\section{Statistical Analysis}

The relative activities of the sIgA preparations were estimated by a decrease in the fluorescence intensity of the initial miRNA (or homooligonucleotide) compared with that of the control (incubation of the substrate without antibodies). The results are reported as the mean and standard deviation of at least 3 independent experiments for each sIgA preparation. The correlation coefficients between different parameters were calculated using Excel 2000 (Microsoft Corp., Redmond, WA). The differences between different groups of sIgAs were estimated by the Mann-Whitney test (Statistica 10; StatSoft Inc., Tulsa, OK); $P<0.05$ was considered statistically significant.

\section{RESULTS AND DISCUSSION}

\section{Purification and Characterization of slgAs}

Immunoglobulin $\mathrm{G}$ and $\mathrm{A}$ molecules from sera of healthy humans (except blood and milk of lactating women) cannot hydrolyze RNA (Nevinsky and Buneva, 2003, 2005; Keinan, 2005; Nevinsky, 2010, 2011, 2016, 2017). In this study, we analyzed the relative RNase activity of individual sIgAs from 7 milk samples of healthy mothers in the hydrolysis of different RNAs (ribo-oligonucleotides) and miRNAs.

Electrophoretically and immunologically homogeneous sIgAs were purified from 7 milk samples by sequential chromatography of milk proteins first on Protein G-Sepharose (to remove IgG) and then on Protein A-Sepharose under conditions that removed nonspecifically bound proteins (Kit et al., 1996; Nevinsky 

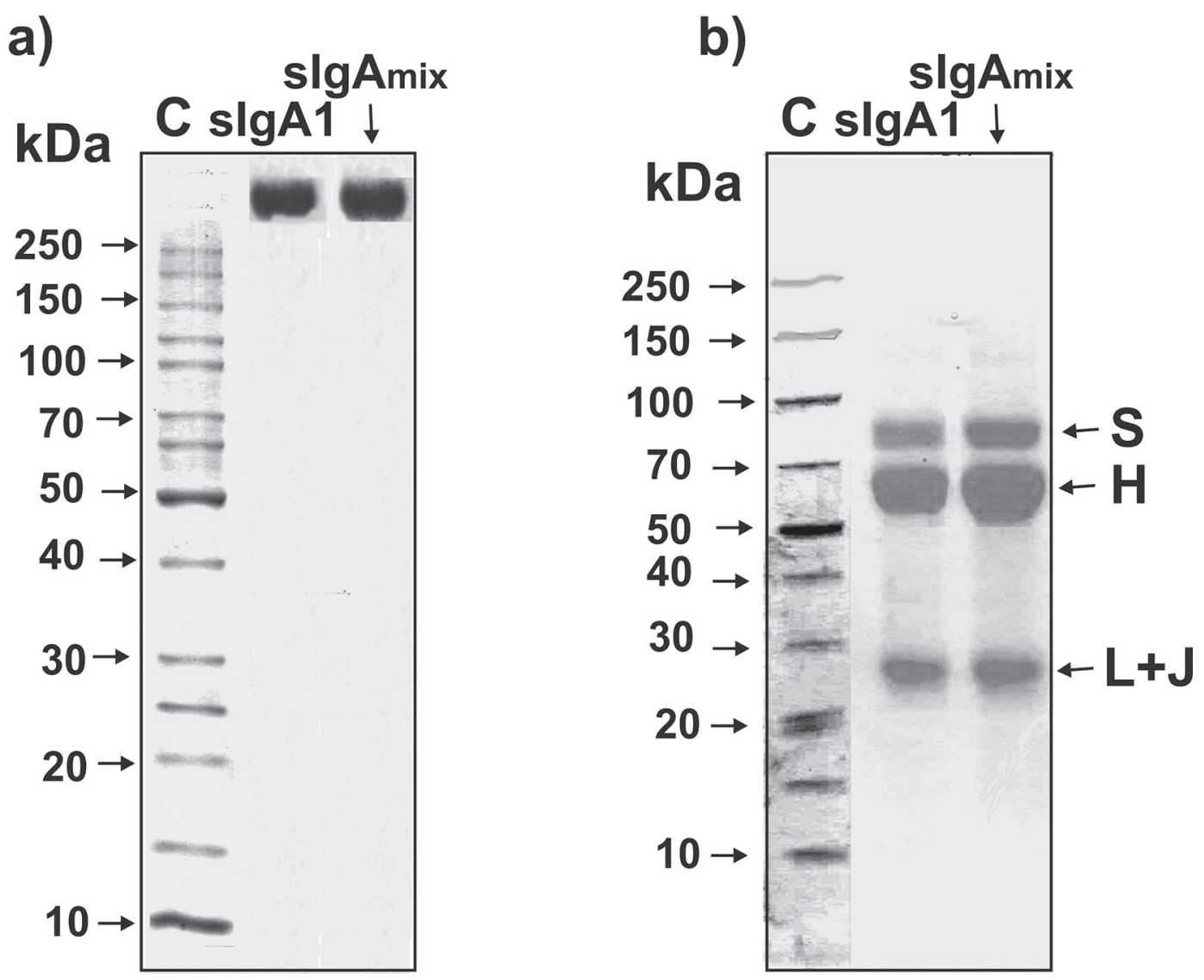

Figure 1. (a) Sodium dodecyl sulfate-PAGE analysis of homogeneity of $9 \mu \mathrm{g}$ of secretory $\operatorname{IgA}(\operatorname{sIgA}) 1$ (lane 1 ) and sIgA $\mathrm{A}_{\text {mix }}$ corresponding to a mixture of individual sIgA (lane 2) from 7 milk preparations in a nonreducing 3-18\% gradient gel followed by staining with silver. (b) SDS-PAGE assay analysis of sIgA1 (lane 1) and $\operatorname{sIg} \mathrm{A}_{\text {mix }}$ (lane 2) components assay in a reducing $12 \%$ gel followed by staining with silver. Under reducing conditions in the presence of dithiothreitol (DTT), antibodies break down into their heavy (H) and light (L) subunits, secretory component (S), and join chain $(\mathrm{J})(\mathrm{b})$. The $\mathrm{L}$ and J chains have similar molecular weights and demonstrate the same electrophoretic mobility $(\mathrm{L}+\mathrm{J})$. The arrows in lane $\mathrm{C}$ (panels a and b) indicate the positions of molecular mass markers.

et al., 1998; Gorbunov et al., 2000, 2005; Karataeva et al., 2006a,b). Then, sIgAs were additionally purified by FPLC gel filtration in an acidic buffer destroying immune complexes. To analyze an "average" situation regarding the homogeneity of sIgAs, a mixture of equal amounts of polyclonal sIgAs from 7 milk samples $\left(\mathrm{sIg} \mathrm{A}_{\text {mix }}\right)$ was prepared. The $\operatorname{sIgA}\left(\mathrm{L}_{4} \mathrm{H}_{4} \mathrm{JS}\right)$ consists of 1 secretory component $(\mathrm{S} ; 72 \mathrm{kDa}), 4$ heavy chains $(\mathrm{H}$; $62 \mathrm{kDa}), 4$ light chains $(\mathrm{L} ; 23 \mathrm{kDa})$, and 1 join chain $(\mathrm{J}$; $23-24 \mathrm{kDa})$. The homogeneity of the typical $\sim 360 \mathrm{kDa}$ sIgAs was confirmed by SDS-PAGE using nonreducing conditions (Figure 1a). After complete reduction of sIgAs using dithiothreitol, only 3 bands (23, 62, and 72 $\mathrm{kDa}$ ), corresponding to $\mathrm{L}$ and $\mathrm{H}$ chains and the secretory component, were revealed (Figure 1b). Because of the similar electrophoretic mobility of the L and J components in the Laemmli system (Buneva et al., 1998; Nevinsky et al., 2000), they were not separated. All 4 components of sIgAs were identified by electrophoresis having 2 coordinates, molecular size and isoelectric point (data not shown).

\section{Application of Strict Criteria}

To prove that the RNase activity belonged to milk sIg $\mathrm{A}_{\text {mix }}$ and not to copurified RNases, previously developed strict criteria (Paul et al., 1989; Nevinsky and Buneva, 2003, 2005; Keinan, 2005; Nevinsky, 2010, 2011, 2016, 2017) were used, the most important of which are as follows: (1) electrophoretic homogeneity of Abs; (2) enzymatic activities should completely disappear from the solution after the addition of Sepharose with immobilized antibodies against analyzed immunoglobulins; (3) after SDS-PAGE, the peak of nuclease activity should coincide with the protein band of antibodies and there should be no other protein bands and no other 
peaks of enzymatic activity. If this criterion is executed, all other known criteria also hold true.

Figure 1a shows that $\operatorname{sIg} \mathrm{A}_{\text {mix }}$ corresponding to gel filtration central parts of the peaks were electrophoretically homogeneous. The RNase activity of gel filtered in an acidic buffer ( $\mathrm{pH} 2.6$ ) $\mathrm{sIg}_{\text {mix }}$ completely disappeared from the solution after addition of Sepharose with immobilized antibodies against human sIgAs.

To exclude possible contamination by hypothetical RNases, sIg $\mathrm{A}_{\text {mix }}$ were subjected to standard SDS-PAGE (Figure 2a) and to in situ analysis using a gel containing polymeric yeast RNA (Figure 2c). After SDSPAGE of $\operatorname{sIg} A_{\text {mix }}$, its RNase activity was detected after extraction of proteins from the excised gel slices only in the gel fragment corresponding to $\operatorname{sIg} \mathrm{A}_{\text {mix }}$ (Figure 2a). In addition, after the SDS-PAGE using gel containing yeast polymeric RNA and refolding of antibodies, the gels stained with ethidium bromide demonstrated dark bands only in the position of intact $\operatorname{sIg} \mathrm{A}_{\text {mix }}$ (Figure 2c). Canonical RNases have much smaller molecular masses $(13-15 \mathrm{kDa})$ than intact sIgAs ( 360 kDa); SDS usually dissociates all protein complexes. Therefore, the detection of RNase activity (lack of ethidium bromide staining) in the gel zones of only intact $\operatorname{sIg} \mathrm{A}_{\text {mix }}$ (Figure 2a) and 2 individual intact sIgAs (Figure 2c), together with the absence of any other activity and protein bands (Figures $2 \mathrm{a}$ and $2 \mathrm{~b}$ ), provide direct evidence that $\mathrm{sIgAs}$ split polymeric RNA. Therefore, contamination of sIgAs with canonical RNases seems unlikely. In addition, IgAs from the blood of healthy men and nonlactating women do not have any catalytic activity (Nevinsky and Buneva, 2003, 2005; Keinan, 2005; Nevinsky, 2010, 2011, 2016, 2017). We have detected different catalytic activities of Abs only in the milk and blood of lactating mothers.

\section{Hydrolysis of Homo-Oligonucleotides}

To estimate the RNase activity of individual sIgAs, fluorescent (Flu) derivatives of Flu- $(\mathrm{pA})_{23}$, Flu- $(\mathrm{pU})_{23}$, and Flu- $(\mathrm{pC})_{23}$, as well as Flu-miR-137, Flu-miR-9-5p, Flu-miR-219-2-3p, and Flu-miR-219a-5p were used, as in Ermakov et al. (2018a,b). Figure 3 demonstrates several typical examples of homo-oligonucleotide (homoON) hydrolysis. The measured relative sIgA activities in the hydrolysis of 3 homo-ON under the same con- a)

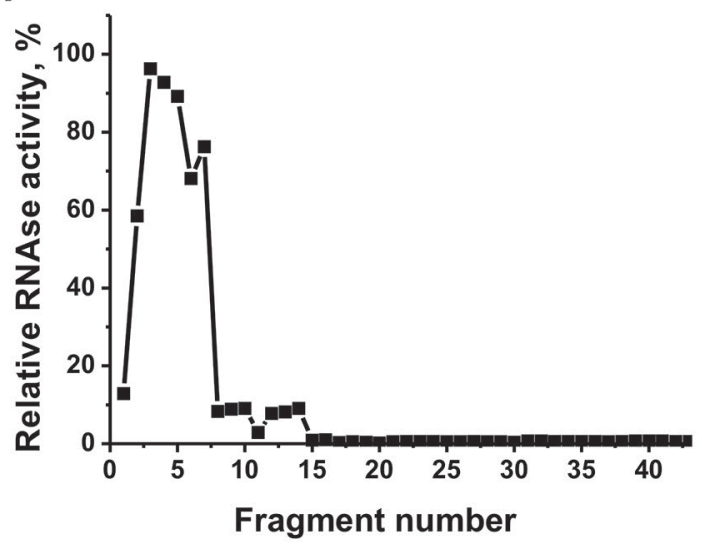

b)

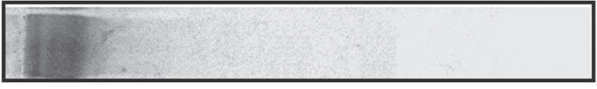

$\operatorname{sig} A$ c) 1234

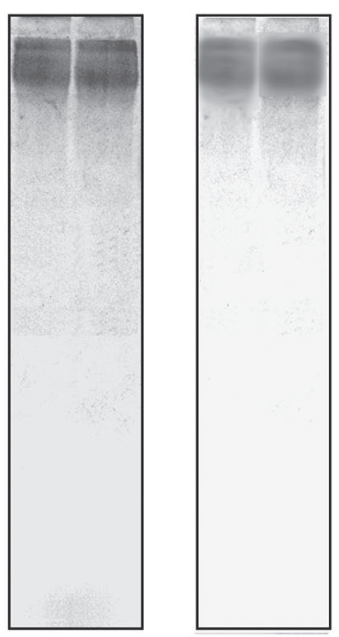

\section{$\operatorname{sig} A$}

Figure 2. Verification of the strict criteria to demonstrate that the RNase activity of secretory IgA (sIgA) is an intrinsic property of antibodies. (a) Analysis of RNase activity of $\operatorname{sIgA}_{\text {mix }}$ (mixture of individual sIgA from 7 milk preparations; relative activity, \%; ) after SDS-PAGE in the hydrolysis of 5'-Flu-(pA) ${ }_{23}$ (ribo-oligonucleotide with fluorescein isothiocyanate marker, Flu); complete hydrolysis of 5 '-Flu-(pA) $)_{23}$ for $5 \mathrm{~h}$ was assumed to represent $100 \%$. (b) Position of sIgA mix on the gel after SDS-PAGE. The error in the initial rate determination from 2 experiments in each case did not exceed 7 to 10\%. (c) Assay of RNase activity of 2 sIgA preparations in-gel containing polymeric yeast RNA (lanes 3 and 4). RNA in the gel is stained with ethidium bromide; in fragments of the gel where RNA is hydrolyzed by RNases, there is no color. For example, there will be 10 protein bands of RNase in the gel, so there will be 10 uncolored bands. Therefore, RNase activity of sIgAs was revealed by ethidium bromide staining as a dark band on the fluorescent background. A part of the gel was stained with Coomassie R250 to show the position of intact SIgA (lanes 1 and 2). 
a) Hydrolysis of Flu-(pA) $)_{23}$

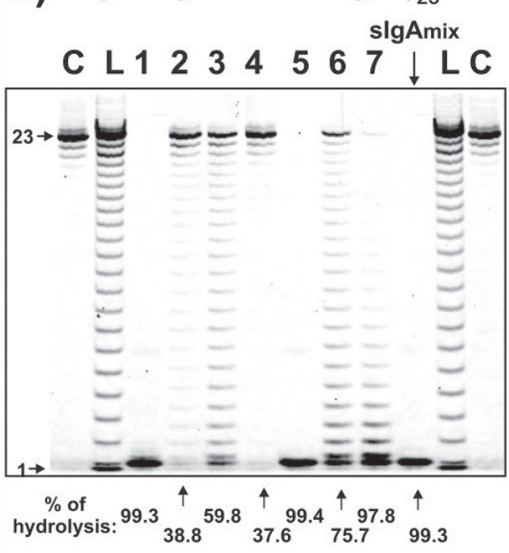

b) Hydrolysis of Flu- $(\mathrm{pU})_{23}$

slgAmix

C L $1 \begin{array}{lllllllllll}2 & 3 & 4 & 5 & 6 & 7 & \downarrow & \text { LC }\end{array}$

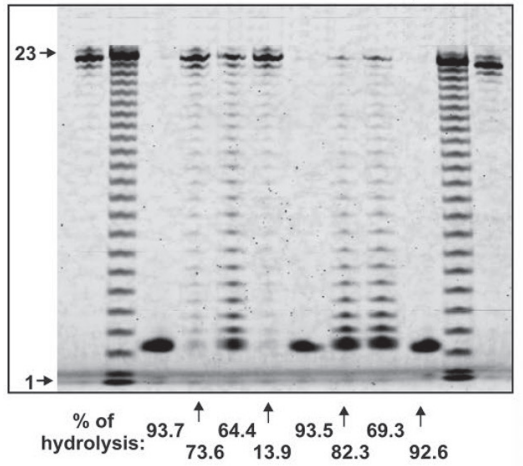

C) Hydrolysis of Flu- $(\mathrm{pC})_{23}$

slgAmix

C L 1223445667 L L C

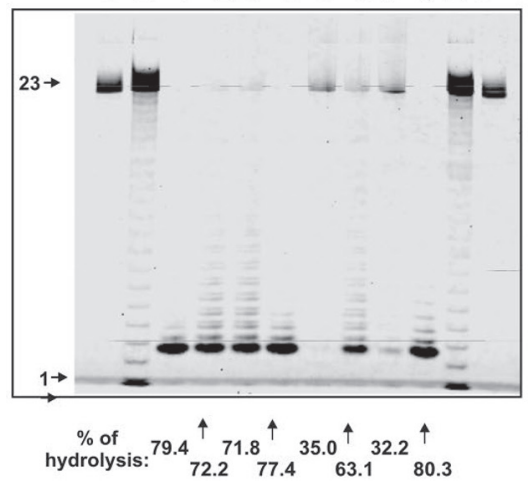

Figure 3. The patterns of hydrolysis of Flu-homo-oligonucleotides $(0.01 \mathrm{mg} / \mathrm{mL}$; oligonucleotide with fluorescein isothiocyanate marker, Flu) by 7 individual secretory $\operatorname{IgAs}(\operatorname{sIgA}$; lanes 1 to 7 ) and $\operatorname{sIgA}$ mix $(40 \mu \mathrm{g} / \mathrm{mL})$. The hydrolysis products were detected after incubation of the reaction mixture for $1 \mathrm{~h}$ followed by analysis of the products using 20\% PAGE and standard estimation of the relative fluorescence $(\%)$ of intact substrate and products of its hydrolysis. The percentage of Flu- $(\mathrm{pN})_{23}$ hydrolysis in each preparation (average of 3 independent experiments) are indicated at the bottom of panels a to c. Lane L shows markers of oligonucleotide length, and lane $\mathrm{C}$ indicates substrates incubated without sIgA (controls). ditions differed significantly $(P<0.05)$. However, all 7 sIgAs had detectable or high RNase activity in the hydrolysis of all homo-ONs. Some sIgAs hydrolyzed $(\mathrm{pA})_{23}$ (Figure 3a), $(\mathrm{pU})_{23}$ (Figure $3 \mathrm{~b}$ ), and $(\mathrm{pC})_{23}$ (Figure 3c) more weakly than others. For example, sIgA4 hydrolyzed $(\mathrm{pA})_{23}(38.6 \%)$ and $(\mathrm{pU})_{23}(13.9 \%)$ slower than other Abs, but its efficiency in hydrolysis of $(\mathrm{pC})_{23}(77.4 \%)$ was relatively high. Overall, the average values of the activities of $7 \mathrm{sIgAs}$ in the hydrolysis of $(\mathrm{pA})_{23},(\mathrm{pU})_{23}$, and $(\mathrm{pC})_{23}(61.7 \pm 19.6,70.1 \pm 27.3$, and $72.6 \pm 27.7 \%$, respectively) were, to some extent, comparable. The correlation coefficients $(\mathrm{r})$ of the hydrolysis between $(\mathrm{pA})_{23}$ and $(\mathrm{pU})_{23}$ was positive $(0.71)$, whereas they were negative between $(\mathrm{pA})_{23}$ and $(\mathrm{pC})_{23}$ $(-0.61)$ and between $(\mathrm{pU})_{23}$ and $(\mathrm{pC})_{23}(-0.33)$. All $(\mathrm{pN})_{23}$ were hydrolyzed with cleaving of all internucleotide bonds with comparable efficiency with formation of oligonucleotides of very different lengths. One of the final products of $(\mathrm{pA})_{23}$ hydrolysis was mononucleotide $\left[(\mathrm{pA})_{1}\right]$, but in the case of $(\mathrm{pU})_{23}$ and $(\mathrm{pC})_{23}$, trinucleotides $\left[(\mathrm{pN})_{3}\right]$ were formed (Figure 3 ).

\section{Hydrolysis of MiRNAs}

It is known that some miRNAs can regulate several hundred genes in different mammals (Miller and Wahlestedt, 2010; Melnik and Schmitz, 2017). Previously, hydrolysis of miR-9-5p, miR-219-2-3p, miR-219a$5 \mathrm{p}$, and miR-137 by $\operatorname{IgG}$ from sera of patients with schizophrenia (SCZ IgG) was analyzed (Ermakov et al., 2018a,b); these miRNAs are also found in human milk (Alsaweed et al., 2015a, 2016c).

MicroRNA-219 plays an important role in the differentiation of oligodendrocytes and the myelination of axons of neuronal cells (Murai et al., 2016). Figure 4a shows typical patterns of miR-219a-5p hydrolysis by 7 sIgAs. All sIgAs differed in the rate of hydrolysis of miR-219a-5p. Interestingly, the major cleavage sites were $4 \mathrm{U}-5 \mathrm{U}$ and $9 \mathrm{C}-10 \mathrm{~A}$, moderate sites of hydrolysis were $7 \mathrm{U}-8 \mathrm{C}$ and $8 \mathrm{C}-9 \mathrm{C}$, and $15 \mathrm{C}-16 \mathrm{~A}$ was a weak splitting site. However, sIgA2 to sIgA4 hydrolyzed miR-219a-5p poorly at all of these sites. The percent hydrolysis for different sIgAs varied from 28.1 to $96.4 \%$; the average efficiency of miR-219a-5p cleavage by all 7 Abs was $64.7 \pm 26.6 \%$.

Figure $4 \mathrm{~b}$ shows the products of miR-219-2-3p hydrolysis by the 7 sIgAs, which differed in efficiency of hydrolysis. The major sites of cleavage were $3 \mathrm{~A}-4 \mathrm{~A}$ and $9 \mathrm{G}-10 \mathrm{G}$; moderate sites were $7 \mathrm{G}-8 \mathrm{U}$ and $8 \mathrm{U}-9 \mathrm{G}$. Interestingly, sIgA2 and sIgA3 poorly hydrolyzed miR219a-5p (Figure 4a), but hydrolyzed miR-219-2-3p to a greater degree. However, they cleaved miR-219-2-3p not in several specific sites but also in many additional sites, to some extent nonspecific. Secretory IgA4 weakly 
a)

RNA sequence of 21-mer miR-219a-5p

$\begin{array}{lllllllllllllllllllll}U & C & U & U & A & A & C & G & C & A & A & A & A & C & U & G & U & U & A & G & U\end{array}$

$\begin{array}{lllllllllllllllllllll}21 & 20 & 19 & 18 & 17 & 16 & 15 & 14 & 13 & 12 & 11 & 10 & 9 & 8 & 7 & 6 & 5 & 4 & 3 & 2 & 1\end{array}$

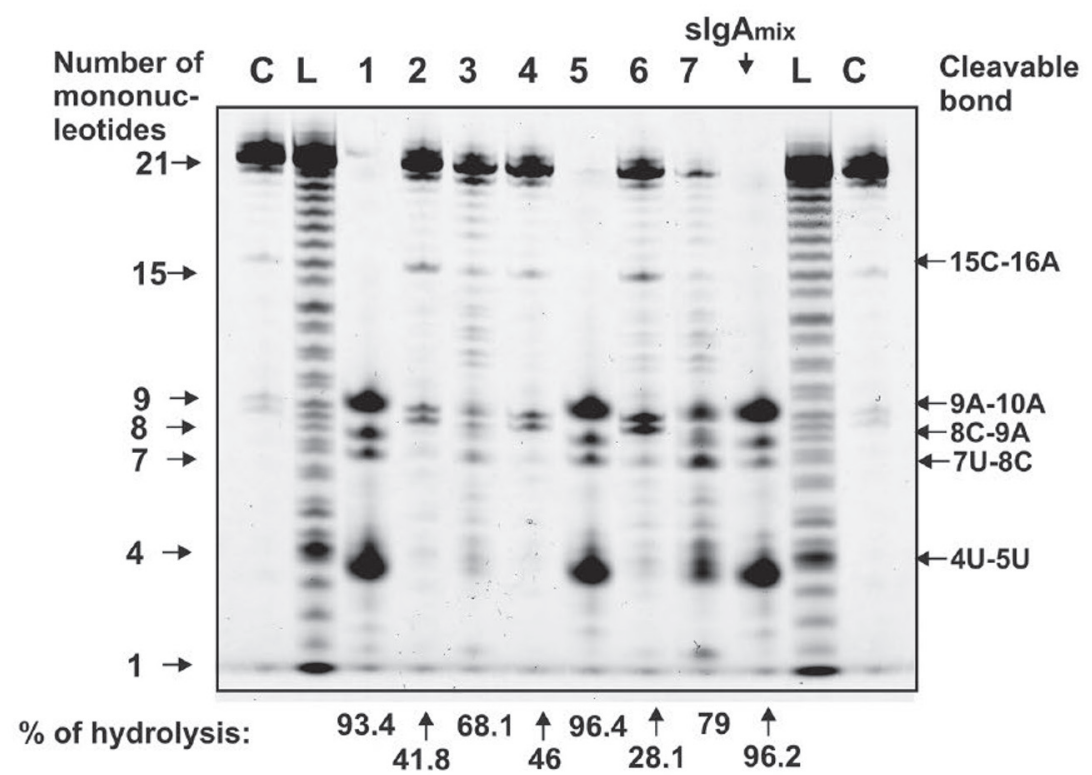

b) RNA sequence of 22-mer miR-219a-2-3p

$\begin{array}{lllllllllllllllllllllll}\text { U } & G & \text { U } & \text { C } & \text { U } & A & \text { C } & \text { A } & \text { G } & \text { G } & \text { U } & \text { C } & \text { G } & \text { G } & \text { U } & \text { G } & \text { U } & \text { U } & \text { A } & \text { A } & \text { G } & \text { A } \\ 22 & 21 & 20 & 19 & 18 & 17 & 16 & 15 & 14 & 13 & 12 & 11 & 10 & 9 & 8 & 7 & 6 & 5 & 4 & 3 & 2 & 1\end{array}$

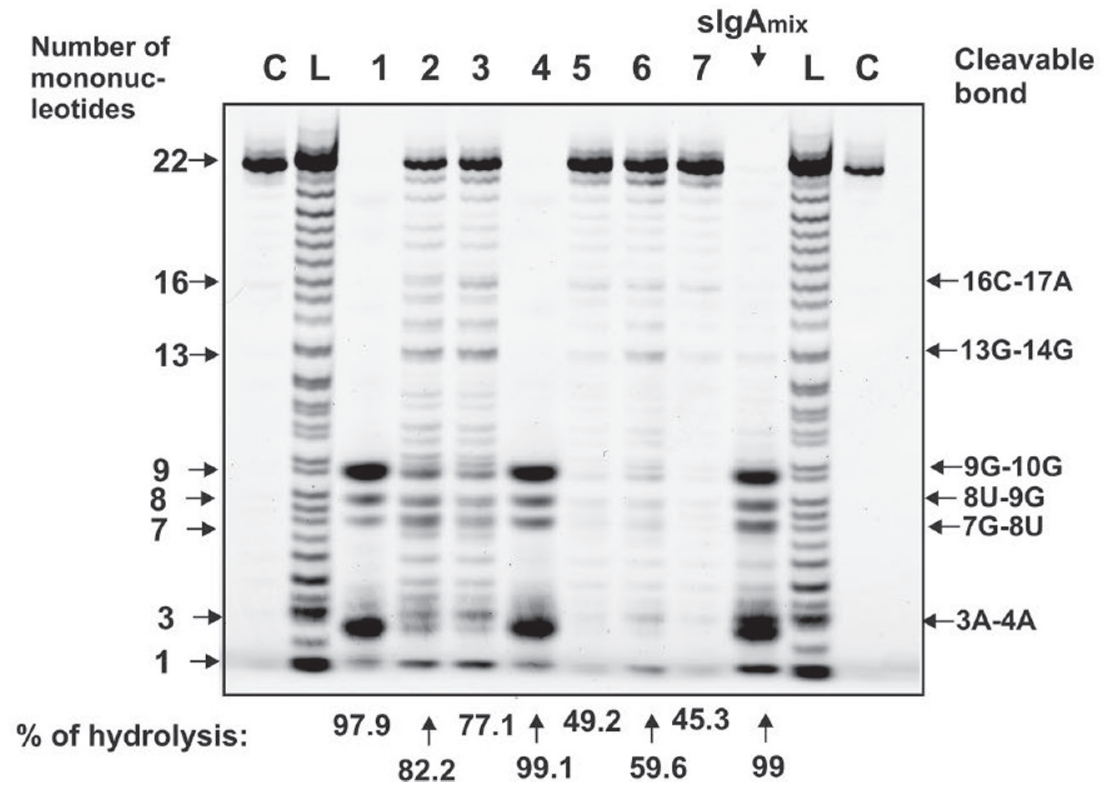

Figure 4. The patterns of hydrolysis of $0.01 \mathrm{mg} / \mathrm{mL}$ Flu-miR-219a-5p (a) and Flu-miR-219-2-3p (b) by 7 secretory IgA (sIgA; lanes 1-7; $0.04 \mathrm{mg} / \mathrm{mL}$ ) from human milk. The hydrolysis products were detected by the fluorescent residue (Flu) on their $5^{\prime}$-ends after incubation of the reaction mixture for $1 \mathrm{~h}$. The numbers of $\operatorname{sIgA}$ and $\operatorname{sIgA}$ mix, cleavable bonds, lengths of the oligonucleotide products, and the percentage of hydrolysis of microRNAs by each preparation (average of 3 independent experiments) are indicated in both panels. Lane L shows markers of oligonucleotide length, and lane C indicates substrates incubated without sIgA (controls). 
a)

RNA sequence of 23-mer miR-137
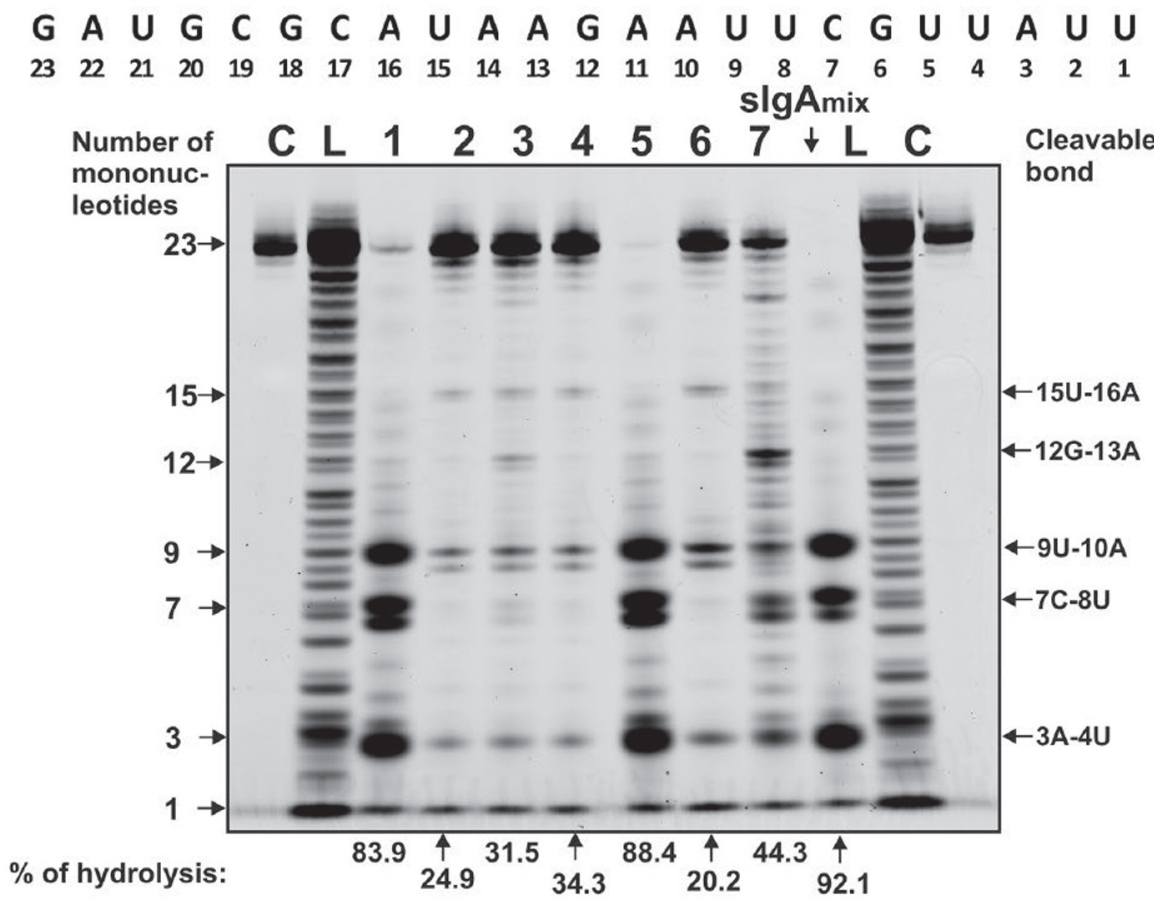

b) RNA sequence of 23-mer miR-9-5p

$\begin{array}{ccccccccccccccccccccccc}A & G & \text { U } & A & \text { U } & \text { G } & \text { U } & \text { C } & \text { G } & \text { A } & \text { U } & \text { C } & \text { U } & \text { A } & \text { U } & \text { U } & \text { G } & \text { G } & \text { U } & \text { U } & \text { U } & \text { C } & \text { U } \\ 23 & 22 & 21 & 20 & 19 & 18 & 17 & 16 & 15 & 14 & 13 & 12 & 11 & 10 & 9 & 8 & 7 & 6 & 5 & 4 & 3 & 2 & 1\end{array}$

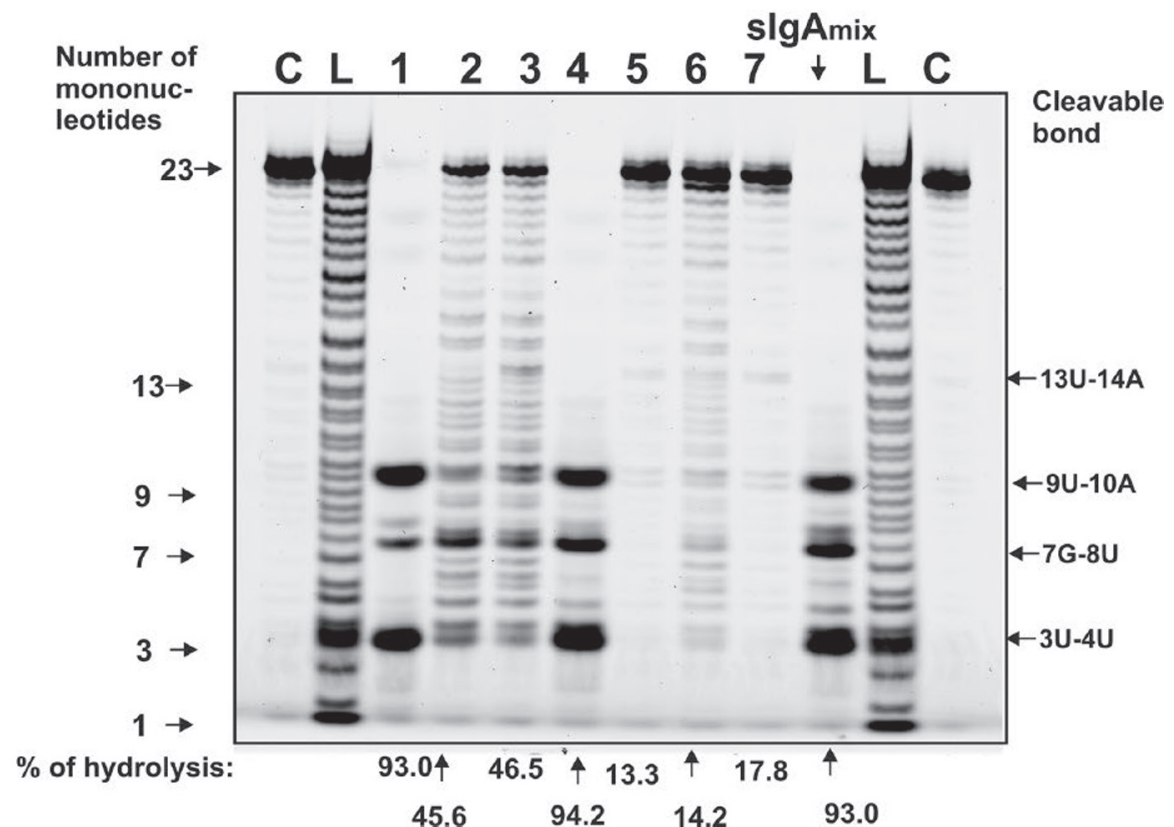

Figure 5. The patterns of hydrolysis of $0.01 \mathrm{mg} / \mathrm{mL}$ Flu-miR-137 (a) and Flu-miR-9-5p (b) by 7 secretory IgA (sIgA; lanes 1-7; $0.04 \mathrm{mg} /$ $\mathrm{mL}$ ) from human milk. The hydrolysis products were detected by the fluorescent residue (Flu) on their $5^{\prime}$-ends after incubation of the reaction mixture for $1 \mathrm{~h}$. The numbers of $\operatorname{sIgA}$ and $\operatorname{sIg} \mathrm{A}_{\text {mix }}$, cleavable bonds, lengths of the oligonucleotide products, and the percentage of hydrolysis of microRNAs by each preparation (average of 3 independent experiments) are indicated in both panels. Lane L shows markers of oligonucleotide length, and lane $\mathrm{C}$ indicates substrates incubated without $\operatorname{sgA}$ (controls). 
hydrolyzed miR-219a-5p, whereas it cleaved miR-219$2-3 p$ very effectively in major sites of its hydrolysis. At the same time, sIgA5 and sIgA7 hydrolyzed miR-219a$5 \mathrm{p}$ effectively in the major sites but showed weak activity against miR-219-2-3p, leading to many products without well-pronounced preferential cleavage sites. The percent of miR-219-2-3p hydrolysis by all 7 sIgAs varied from 45.3 to $97.9 \%$; average relative activity of miR-219-2-3p cleavage was $72.9 \pm 22.0 \%$. The correlation coefficient for the relative activities of hydrolysis of miR-219a-5p and miR-219-2-3p was low and negative $(-0.18)$.

We were interested in whether the relative activities of sIgAs in the hydrolysis of the miR-219 microRNAs correlated with hydrolysis of homo-ONs. We estimated correlation coefficients for miR-219a-5p and the $3(\mathrm{pN})$ ${ }_{\mathrm{n}}:(\mathrm{pA})_{23}(\mathrm{r}=0.76),(\mathrm{pU})_{23}(\mathrm{r}=0.44)$, and $(\mathrm{pC})_{23}(\mathrm{r}$ $=-0.41)$; and for miR-219-2-3p: $(\mathrm{pA})_{23}(\mathrm{r}=-0.54)$, $(\mathrm{pU})_{23}(\mathrm{r}=-0.44)$, and $(\mathrm{pC})_{23}(\mathrm{r}=0.92)$. Thus, hydrolysis of miR-219a-5p correlated better (and positively) with that of $(\mathrm{pA})_{23}$, whereas hydrolysis of miR-219-2-3p correlated better with that of $(\mathrm{pC})_{23}$.

Figure 5 demonstrates typical patterns of miR-137 and miR-9-5p hydrolysis by the 7 individual sIgAs. All sIgAs were able to cleave miR-137 but with different efficiency (Figure 5a). The major cleavage sites of miR137 were $3 \mathrm{~A}-4 \mathrm{U}, 7 \mathrm{C}-8 \mathrm{U}$, and $9 \mathrm{U}-10 \mathrm{~A}$, whereas $\operatorname{sigA} 7$ additionally effectively cleaved at 12G-13A (Figure 5a). Interestingly, similar to hydrolysis of miR-219-2-3p, sIgA2, sIgA3, and sIgA4 hydrolyzed miR-317 poorly at all sites. The percentage miR-137 hydrolysis varied from 20.2 to $88.4 \%$; average efficiency of miR-137 hydrolysis by all 7 abzymes was $46.8 \pm 28.0 \%$ (Figure 5a). Correlation coefficients for miR-137 and other substrates were estimated: $(\mathrm{pA})_{23}(\mathrm{r}=0.70),(\mathrm{pU})_{23}(\mathrm{r}=$ $0.49)$, and $(\mathrm{pC})_{23}(\mathrm{r}=-0.3)$, miR-219a-5p $(\mathrm{r}=0.90)$, miR-219a-2-3p $(\mathrm{r}=-0.06)$. Thus, maximal correlation of miR-137 hydrolysis was observed with $(\mathrm{pA})_{23}$ and miR-219a-5p; the hydrolysis of miR-137 and miR-219a$5 \mathrm{p}$ was also strongly correlated $(\mathrm{r}=0.76)$.

Products of hydrolysis of miR-9-5p by the $7 \mathrm{sIgAs}$ are shown in Figure 5b. The 7 sIgAs split miR-9-5p in dif- ferent ways; $\operatorname{sIgA} 5$ and $\operatorname{sIgA} 6$ were almost not capable of hydrolyzing miR-9-5p. For the remaining 5 preparations, maximum cleavage was observed at $3 \mathrm{U}-4 \mathrm{U}$, 7G-8U, and 9U-10A (Figure 5b). Secretory IgA2 and sIgA3, which poorly hydrolyzed miR-219a-5p (Figure 4a), cleaved miR-9-5p in a similarly nonspecific way, with formation of many products, but the major sites of hydrolysis were the same. The percentage of miR-95p hydrolysis ranged from 13.3 to $93.0 \%$; average relative activity of miR-9-5p cleavage by all 7 sIgAs was $46.4 \pm 35.1 \%$ (Figure 5b). Correlation coefficients for miR-9-5p with other oligonucleotides were estimated: $(\mathrm{pA})_{23}(\mathrm{r}=-0.37),(\mathrm{pU})_{23}(\mathrm{r}=0.48),(\mathrm{pC})_{23}(\mathrm{r}=0.78)$, miR-219a-5p $(\mathrm{r}=0.03)$, miR-219a-2-3p $(\mathrm{r}=0.95)$, and miR-137 $(\mathrm{r}=0.12)$. The data on all correlation coefficients is given in Table 1.

Spatial structures of miRNAs having minimal free energy were calculated in Ermakov et al. (2018a,b). Immunoglobulin G-dependent cleavage sites of 4 miRNAs from sera of patients with SCZ was found previously by Ermakov et al. (2018a,b). Figures 6a and 6b demonstrate positions and relative average percentages of hydrolysis of miR-219a-5p by 7 sIgAs from milk and by SCZ IgGs. Figures $6 \mathrm{c}$ and $6 \mathrm{~d}$ show the average values of hydrolysis of miR-219-2-3p by milk sIgAs and SCZ IgGs. Similar comparisons were performed for hydrolysis of miR-137 (Figures 7a and 7b) and miR-95p (Figures 7c and 7d). All major and moderate sites of miRNA hydrolysis differed between milk sIgAs and SCZ IgGs. For SCZ IgGs, the cleavage sites of miRNAs were largely located in loops, whereas sIgAs efficiently hydrolyzed miRNAs not only in loops but also in duplex fragments of these substrates.

It was previously shown that $\operatorname{IgG}$ and $\operatorname{IgA}$ from healthy donors cannot hydrolyze RNA or DNA (Vlassov et al., 1998, 1999; Vlasov et al., 1998, 1999). However, IgG and IgA from the milk of healthy mothers can hydrolyze supercoiled DNAs and polymeric RNAs (Buneva et al., 1998; Nevinsky et al., 2000).

In this study, we analyzed the RNase activity of $\operatorname{sig} \mathrm{A}$ from human milk in the hydrolysis of different homoONs and miRNAs. We showed that $100 \%$ of the $7 \mathrm{sIgAs}$

Table 1. Correlation coefficients between relative activities of 7 secretory IgA molecules (from 7 human breast milk samples) in the hydrolysis of microRNAs $(\mathrm{miR})$ and oligonucleotides $\left[(\mathrm{pN})_{23}\right]$

\begin{tabular}{lccrrr}
\hline Substrate & $(\mathrm{pU})_{23}$ & $(\mathrm{pC})_{23}$ & miR-219a-5p & miR-219-2-3p & miR-137 \\
\hline$(\mathrm{pA})_{23}$ & 0.71 & -0.61 & 0.76 & -0.54 & 0.70 \\
$(\mathrm{pU})_{23}$ & & -0.33 & 0.44 & -0.44 & 0.49 \\
$(\mathrm{pC})_{23}$ & & -0.41 & -0.92 & -0.37 & 0.48 \\
miR-219a-5p & & & & 0.78 \\
miR-219-2-3p & & & & -0.06 \\
miR-137 & & & & 0.03 \\
\hline
\end{tabular}




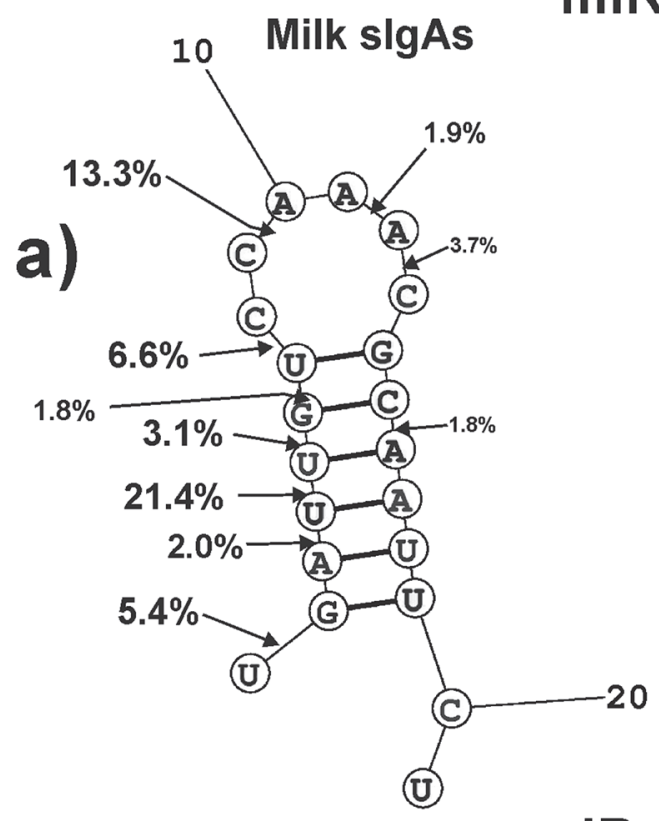

miR-219a-5p

miR-219-2-3p
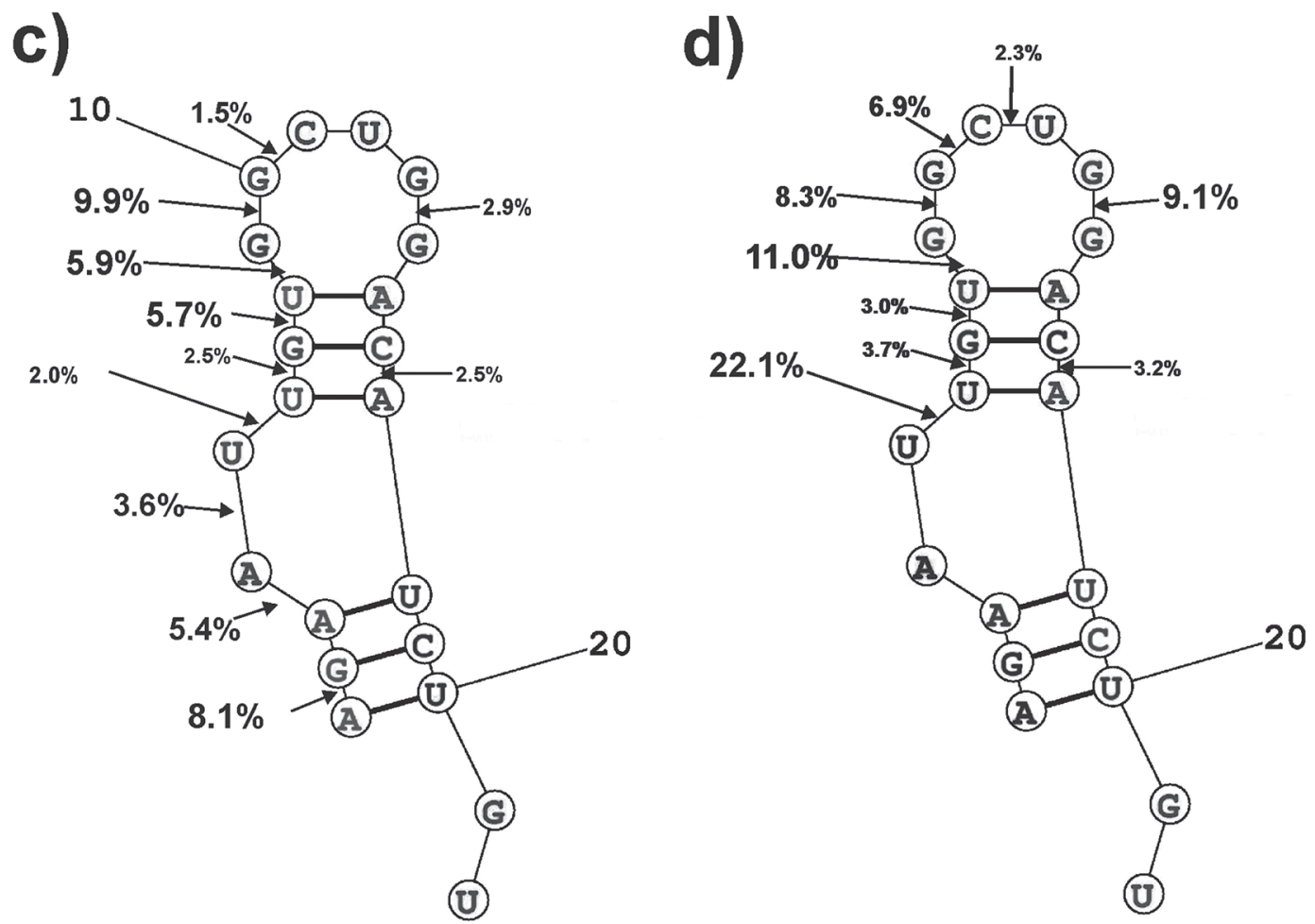

Figure 6. The average efficiency of Flu-miR-219a-5p (a and b) and Flu-miR-219-2-3p (c and d) by 7 secretory IgA (sIgAs; a and c) and by IgG preparations from patients with schizophrenia ( $b$ and $d$ ) at all sites of cleavage. The hydrolysis products were detected by the fluorescent residue (Flu) on their $5^{\prime}$-ends. The average percentage of microRNA cleavage in different sites and the position of major and moderate sites of microRNA hydrolysis by milk sIgA $(\mathrm{a}, \mathrm{c})$ and $\operatorname{IgG}(\mathrm{b}, \mathrm{d})$ are shown. Arrows and numbers show the percentage of hydrolysis of various internucleotide bonds; the numbers 10 and 20 without arrows correspond to the numbers of nucleotide units in RNA. 
studied effectively hydrolyzed homo-ONs and miRNAs. However, the relative hydrolytic activities of the sIgAs were highly dependent on the preparations. All sIgAs hydrolyzed homo-ON almost nonspecifically with the formation of many products of different length (Figure $3)$. The average relative activities in hydrolysis of ho-
mo-ON were comparable and increased in the following order: $(\mathrm{pC})_{23}(61.5 \pm 19.8 \%),(\mathrm{pU})_{23}(70.1 \pm 27.3 \%)$, and $(\mathrm{pA})_{23}(74.1 \pm 27.7 \%)$. However, the correlation coefficients between the efficiency of the hydrolysis of homo-ONs were very different and varied from -0.61 for $(\mathrm{pA})_{23}$ and $(\mathrm{pC})_{23}$ to 0.71 for $(\mathrm{pA})_{23}$ and $(\mathrm{pU})_{23}$.
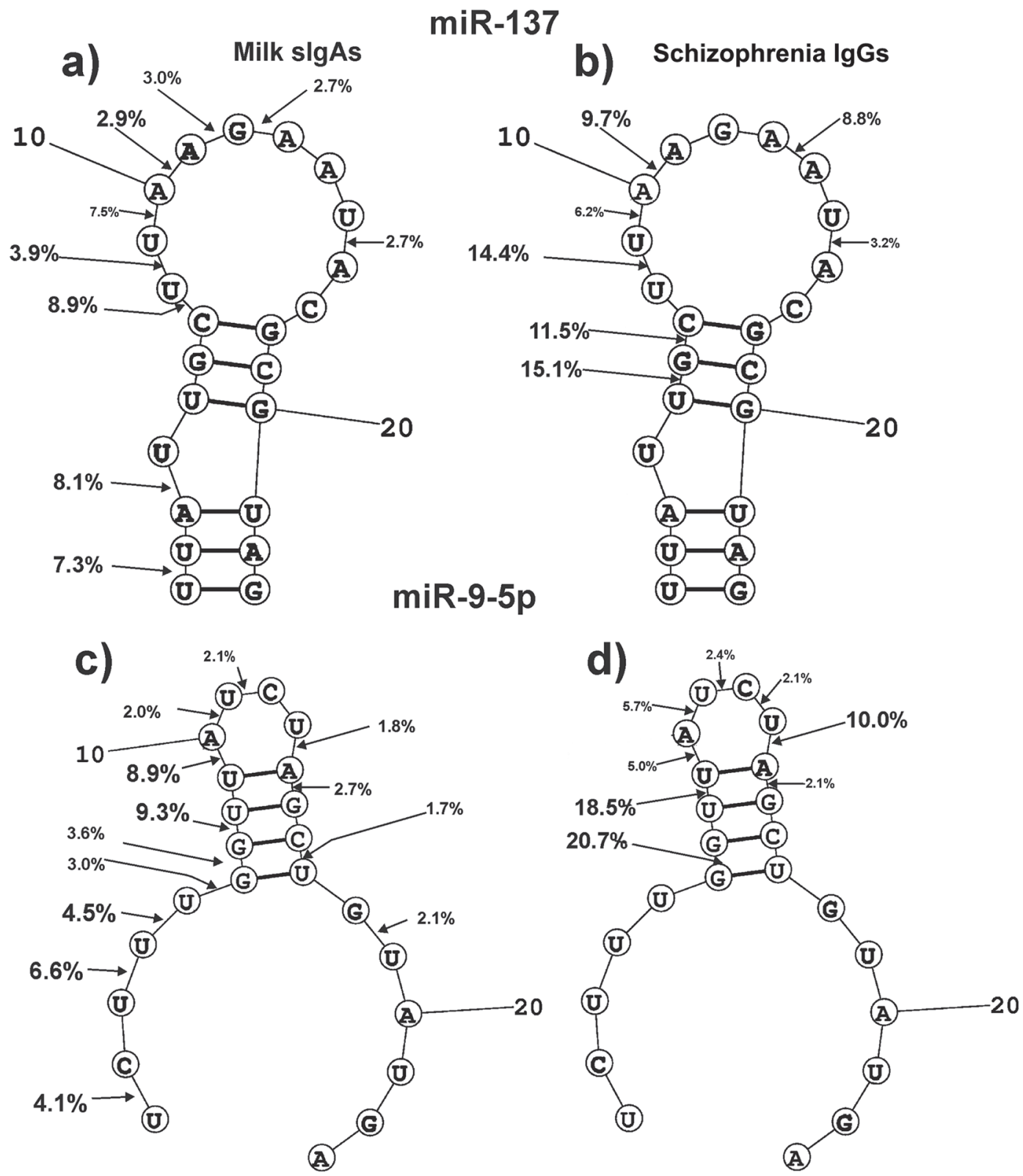

Figure 7. The average efficiency of Flu-miR-137 (a and b) and Flu-miR-9-5p (c and d) by 7 secretory $\operatorname{IgA}$ (a and c) and by IgG preparations from patients with schizophrenia ( $\mathrm{b}$ and $\mathrm{d}$ ) in all sites of cleavage. The hydrolysis products were detected by the fluorescent residue (Flu) on their $5^{\prime}$-ends. The average percentage of microRNA cleavage in different sites and position of major and moderate sites of microRNA hydrolysis by milk sIgA (a, c) and $\operatorname{IgG}(\mathrm{b}, \mathrm{d})$ are shown. Arrows and numbers show the percentage of hydrolysis of various internucleotide bonds; the numbers 10 and 20 without arrows correspond to the numbers of nucleotide units in RNA. 
In addition, one final product of $(\mathrm{pA})_{23}$ hydrolysis was $(\mathrm{pA})_{1}$, whereas for $(\mathrm{pU})_{23}$ and $(\mathrm{pC})_{23}$, mainly trinucleotides $(\mathrm{pN})_{3}$ were formed (Figure 3 ).

In contrast to homo-ONs, the hydrolysis of 4 miRNA was to some extent site-specific. Average relative activities for $7 \mathrm{sIgAs}$ in the hydrolysis of miRNAs increased in the following order: miR-9-5p (46.4 $\pm 35.1 \%)$, miR137 (46.8 $\pm 28.0 \%)$, and miR-219a-5p $(64.7 \pm 26.6 \%)$; average relative cleavage of miR-219-2-3p was $72.9 \pm$ $22.0 \%$.

According to the Mann-Whitney test, there were no significant differences between hydrolysis of these 4 miRNAs: miR-137 and miR-219-2-3p $(P=0.074)$; miR137 and miR-9-5p $(P=0.2)$; miR137 and miR219a-5p $(P=1.0)$; miR-9-5p and miR-219-2-3p $(P=$ $0.44)$; miR-9-5p and miR-219a-5p $(P=0.31)$; and miR219a-5p and miR-219-2-3p $(P=0.12)$.

Interestingly, as in the case of homo-ON, the correlation coefficients of relative activities for all 4 miRNAs between themselves (-18.0 to 0.90) and with homo-ON $(-0.59$ to 0.92$)$ varied widely (Table 1$)$. High correlation coefficients for the hydrolysis of various miRNAs could be related to the level of their homology. However, this factor was not significant in the manifestation of high correlation coefficients. The level of homology between all RNAs was comparable, and efficiency of hydrolysis did not correlate with the level of miRNA homology (correlation coefficient; \% homology): miR137 and miR-9-5p (0.12; 70.6\%); miR-137 and miR-2192-3p (-0.06; 52.0\%); miR-137 and miR-219a-5p (0.90; $56.5 \%)$; miR-9-5p and miR-219a-5p (0.03; 57.9\%); miR-9-5p and miR-219-2-3p (0.12; 59.1\%); miR-219a$5 p$ and miR-219-2-3p (-0.18; 69.6\%).

We cannot exclude the possibility that homology of linear forms of miRNAs is important for the correlation coefficients in the efficiency of hydrolysis. It is possible that specific spatial conformation of miRNA is more important for increased correlation in the efficiency of hydrolysis.

As noted above, the cleavage sites of 4 miRNAs by SCZ IgG were previously found (Ermakov et al., 2018a,b). In the current study, we compared the major splitting sites of 4 miRNAs by IgG from blood of patients with schizophrenia (SCZ IgG) and by sIgAs from breast milk (Figures 6 and 7 ). Only site $9 \mathrm{C}-10 \mathrm{~A}$ of miR-219-5p of SCZ IgG and sIgA were the same, with comparable efficiency of cleavage (Figure $6 \mathrm{a}$ and $6 \mathrm{~b}$ ). The $6 \mathrm{G}-7 \mathrm{U}, 8 \mathrm{C}-9 \mathrm{C}$, and $14 \mathrm{C}-15 \mathrm{G}$ sites were major for miR-219-5p hydrolysis by IgG, but sIgA did not cleave it in these sites. Immunoglobulin $\mathrm{G}$ hydrolyzes miR219-5p in one 2G-7U duplex part, whereas the major site $4 \mathrm{U}-5 \mathrm{U}$ and some additional sites of its cleavage by
sIgAs were located in this part of the miRNA. Overall, the positions of splitting sites in miR-219-5p and the efficiency of hydrolysis in these sites for IgG and $\operatorname{sIg}$ A were very different.

The spatial structure of miR-219-2-3p is more complex than that of miR-219-5p; it has 2 short duplex parts (Figure 6). In contrast to SCZ IgG, for cleavage by $\operatorname{sIgA}$, there were no pronounced major sites of hydrolysis expect 9G-10G, which coincided with a moderate site for IgG. At the same time, in the major sites (5U-6U, 8U-9G, and 13G-14G; 9.1-22.1\%) of hydrolysis of miR-219-2-3p by IgG, this miRNA was very weakly split by $\operatorname{sIgAs}(2.0,5.9$, and $2.9 \%$, Figure $6 \mathrm{c})$. Interestingly, unlike IgGs, sIgAs efficiently hydrolyze this RNA at its duplex part. In general, however, compared with SCZ IgGs, this miRNA is hydrolyzed by milk sIgAs less specifically.

In the major splitting sites of miR-137 by IgGs (5U6G, 6G-7C, and 13A-14A), sIgAs were completely inactive, whereas at the other 2 sites (8U-9U and 10A-11A), very weak hydrolysis was observed compared with the IgGs. In contrast to IgGs, sIgAs cleaved miR-137 in its duplex part. In general, hydrolysis of miR-137 by sIgAs was less specific than hydrolysis by IgGs.

Major sites of miR-9-5p splitting by SCZ IgGs (6G$7 \mathrm{G}, 8 \mathrm{U}-9 \mathrm{U}, 13 \mathrm{U}-14 \mathrm{~A})$ and by milk sIgAs $(7 \mathrm{G}-8 \mathrm{U}, 9 \mathrm{U}-$ $10 \mathrm{~A})$ were different. In addition, IgGs did not cleave miR-9-5p from nucleotide 1 to 6 of its sequence, whereas sIgAs demonstrated 4 moderate sites of hydrolysis in this part of the miRNA.

As noted above, no correlation was found between efficiency of hydrolysis of 4 miRNAs and their homology. In the case of different miRNAs, the following major and moderate splitting sites were found for milk sIgAs and SCZ IgGs: miR-219-5p (U-U, C-A, U-G, G-U, C-C, and G-G); miR-219-2-3p (G-G, G-U, A-G, A-A, U-U, and U-G); miR-137 (G-G, U-G, G-U, A-G, and U-U); and miR-9-5p (U-A, G-U, U-U, U-C, G-G). This means that, in principle, cleavage sites in different miRNAs can fit to different dinucleotides of their sequences. Most likely, the spatial structure of miRNA is, to some extent, a more important factor determining correlations between efficiency of hydrolysis of various miRNA pairs. For example, a maximum positive correlation coefficient (0.9) was observed between the efficiency of sIgA-dependent hydrolysis of miR-219a-5p and miR-137. Both of these miRNAs have the longest duplex part and sIgAs hydrolyze them in these specific fragments. The main difference in the hydrolysis of all 4 miRNAs by SCZ IgGs and milk sIgAs lies in the fact that, unlike IgGs, sIgAs effectively hydrolyzed these substrates in their duplex parts (Figures 6 and 
7). Human blood and milk contain Abs to both singlestranded and double-stranded DNA. It is known that there are classical RNases cleaving RNA only in singlestranded fragments and other RNAses hydrolyzing only double-stranded fragments of RNA. Abzymes hydrolyze in both single- and double-stranded fragments of RNA, with more efficiency in double-stranded ones.

\section{CONCLUSIONS}

We showed here that polyclonal sIgAs from human milk have specific miRNA-hydrolyzing activities. An increase in abzyme activity in milk after childbirth is part of the overall process of restructuring the immune system of women and, as a result, the production of auto-Abs and abzymes triggered by specific immune memory. Secretory IgAs and IgGs from the milk of lactating women possess several unique activities, including phosphorylation of proteins, lipids, and oligosaccharides. It is not yet clear what important role these unique abzymes and antibodies hydrolyzing miRNAs play in protecting infants from harmful factors. However, it should be assumed that the appearance of such abzymes in human milk is not accidental. Although it is widely thought that nutritional infant formulas can replace breast milk, these mixtures do not contain human milk Abs, which provide substantial passive immunity to newborns. Thus, analysis of the biological function of milk Abs appears to be important. It is interesting that, unlike milk sIgAs, IgGs penetrate the blood of newborns through the intestinal epithelium. Therefore, in the next step, it will be important to compare the catalytic functions of breast milk sIgA and IgG antibodies.

\section{ACKNOWLEDGMENTS}

We are very grateful to A. G. Venyaminova and M. I. Meschaninova (Institute of Chemical Biology and Fundamental Medicine, Novosibirsk, Russia) for the synthesis of ONs. This study was supported by the grant from Russian Foundation for Basic Research (Moscow, Russia; 20-015-00156) and from Russian State-funded budget project AAAA-A17-117020210023-1. The authors have stated no conflicts of interest.

\section{REFERENCES}

Alsaweed, M., P. E. Hartmann, D. T. Geddes, and F. Kakulas. 2015b. MicroRNAs in breast milk and the lactating breast: Potential immunoprotectors and developmental regulators for the infant and the mother. Int. J. Environ. Res. Public Health 12:13981-14020. https://doi.org/10.3390/ijerph121113981.
Alsaweed, M., A. R. Hepworth, C. Lefèvre, P. E. Hartmann, D. T. Geddes, and F. Hassiotou. 2015a. Human milk microRNA and total RNA differ depending on milk fractionation. J. Cell. Biochem. 116:2397-2407. https://doi.org/10.1002/jcb.25207.

Alsaweed, M., C. T. Lai, P. E. Hartmann, D. T. Geddes, and F. Kakulas. 2016a. Human milk cells contain numerous miRNAs that may change with milk removal and regulate multiple physiological processes. Int. J. Mol. Sci. 17:956. https://doi.org/10.3390/ ijms17060956.

Alsaweed, M., C. T. Lai, P. E. Hartmann, D. T. Geddes, and F. Kakulas. 2016b. Human milk cells and lipids conserve numerous known and novel miRNAs, some of which are differentially expressed during lactation. PLoS One 11:e0152610. https://doi.org/10.1371/ journal.pone.0152610.

Alsaweed, M., C. T. Lai, P. E. Hartmann, D. T. Geddes, and F. Kakulas. 2016c. Human milk miRNAs primarily originate from the mammary gland resulting in unique miRNA profiles of fractionated milk. Sci. Rep. 6:20680. https://doi.org/10.1038/srep20680.

Amino, N., H. Tada, and Y. Hidaka. 1999. Postpartum autoimmune thyroid syndrome: A model of aggravation of autoimmune disease. Thyroid 9:705-713. https://doi.org/10.1089/thy.1999.9.705.

Andryushkova, A. A., I. A. Kuznetsova, V. N. Bineva, L. B. Toporkova, L. V. Sakhno, M. A. Tikhonova, E. R. Chernykh, I. A. Orlovskaya, and G. A. Nevinsky. 2007. Formation of different abzymes in autoimmune-prone MRL-lpr/lpr mice is associated with changes in colony formation of haematopoetic progenitors. J. Cell. Mol. Med. 11:531-551. https://doi.org/10.1111/j.1582-4934.2007.00048.x.

Andryushkova, A. A., I. A. Kuznetsova, I. A. Orlovskaya, V. N. Buneva, and G. A. Nevinsky. 2006. Antibodies with amylase activity from the sera of autoimmune-prone MRL/MpJ-lpr mice. FEBS Lett. 580:5089-5095. https://doi.org/10.1016/j.febslet.2006.08 .036 .

Andryushkova, A. A., I. A. Kuznetsova, I. A. Orlovskaya, V. N. Buneva, and G. A. Nevinsky. 2009. Nucleotide- hydrolyzing antibodies from the sera of autoimmune-prone MRL-lpr/lpr mice. Int. Immunol. 21:935-945. https://doi.org/10.1093/intimm/dxp060.

Aulova, K. S., L. B. Toporkova, J. A. Lopatnikova, A. A. Alshevskaya, S. V. Sennikov, V. N. Buneva, T. Budde, S. G. Meuth, N. A. Popova, I. A. Orlovskaya, and G. A. Nevinsky. 2017. Changes in haematopoietic progenitor colony differentiation and proliferation and the production of different abzymes in EAE mice treated with DNA. J. Cell. Mol. Med. 21:3795-3809. https://doi.org/10.1111/ jcmm.13289.

Buneva, V. N., T. G. Kanyshkova, A. V. Vlassov, D. V. Semenov, D. Khumankov, L. R. Breusova, and G. A. Nevinsky. 1998. Catalytic DNA- and RNA-hydrolyzing antibodies from milk of healthy human mothers. Appl. Biochem. Biotechnol. 75:63-76. https://doi .org/10.1007/BF02787709.

Buneva, V. N., A. N. Kudryavtseva, A. V. Gal'vita, V. V. Dubrovskaya, O. V. Khokhlova, I. A. Kalinina, V. A. Galenok, and G. A. Nevinsky. 2003. Dynamics of antibody nuclease activity in blood of women during pregnancy and lactation. Biochemistry (Mosc.) 68:890-900. https://doi.org/10.1023/A:1025703132523.

Chernikov, I. V., D. V. Gladkikh, M. I. Meschaninova, A. G. Ven'yaminova, M. A. Zenkova, V. V. Vlassov, and E. L. Chernolovskaya. 2017. Cholesterol-containing nuclease-resistant siRNA. Accumulates in tumors in a carrier-free mode and silences MDR1 gene. Mol. Ther. Nucleic Acids 6:209-220. https://doi.org/10 .1016/j.omtn.2016.12.011.

Dayan, C. M., and G. H. Daniels. 1996. Chronic autoimmune thyroiditis. N. Engl. J. Med. 335:99-107. https://doi.org/10.1056/ NEJM199607113350206.

Doronin, V. B., T. A. Parkhomenko, A. Korablev, L. B. Toporkova, J. A. Lopatnikova, A. A. Alshevskaja, S. V. Sennikov, V. N. Buneva, T. Budde, S. G. Meuth, I. A. Orlovskaya, N. A. Popova, and G. A. Nevinsky. 2016. Changes in different parameters, lymphocyte proliferation and hematopoietic progenitor colony formation in EAE mice treated with myelin oligodendrocyte glycoprotein. J. Cell. Mol. Med. 20:81-94. https://doi.org/10.1111/jcmm.12704. 
Ermakov, E. A., S. A. Ivanova, V. N. Buneva, and G. A. Nevinsky. 2018a. Hydrolysis by catalytic IgGs of microRNA specific for patients with schizophrenia. IUBMB Life 70:153-164. https://doi .org/10.1002/iub.1712.

Ermakov, E. A., S. A. Ivanova, V. N. Buneva, and G. A. Nevinsky. 2018b. Blood-derived RNA- and microRNA-hydrolyzing IgG antibodies in schizophrenia patients. Biochemistry (Mosc.) 83:507526. https://doi.org/10.1134/S0006297918050048.

Ferro, E., C. E. Bena, S. Grigolon, and C. Bosia. 2019. From endogenous to synthetic microRNA-mediated regulatory circuits: An overview. Cells 8:1540. https://doi.org/10.3390/cells8121540.

Freeman, R., H. Rosen, and B. Thysen. 1986. Incidence of thyroid dysfunction in an unselected postpartum population. Arch. Intern. Med. 146:1361-1364. https://doi.org/10.1001/archinte.1986 .00360190137019 .

Golan-Gerstl, R., Y. Elbaum Shiff, V. Moshayoff, D. Schecter, D. Leshkowitz, and S. Reif. 2017. Characterization and biological function of milk-derived miRNAs. Mol. Nutr. Food Res. 61:1700009. https: //doi.org/10.1002/mnfr.201700009.

Gorbunov, D. V., N. A. Karataeva, V. N. Buneva, and G. A. Nevinsky. 2005. Lipid kinase activity of antibodies from milk of clinically healthy human mothers. Biochim. Biophys. Acta 1735:153-166. https://doi.org/10.1016/j.bbalip.2005.06.007.

Gorbunov, D. V., D. V. Semenov, M. V. Shipitsin, Yu. Yu. Kit, T. G. Kanyshkova, V. N. Buneva, and G. A. Nevinsky. 2000. Phosphorylation of minor lipids of human milk tightly bound to secretory immunoglobulin A. Russ. J. Immunol. 5:267-278.

Hanson, L. A., B. Carlsson, and J. R. Cruz. 1979. T cell regulation of IgA synthesis. Pages 145-157 in Immunology of Breast Milk. P. L. Ogra and D. H. Dayton ed. Raven Press, New York, NY.

Hanson, L. A., M. Hahn-Zoric, M. Berndes, R. Ashraf, V. Herias, F. Jalil, T. I. Bhutta, A. Laeeq, and I. Mattsby-Baltzer. 1994. Breast feeding: Overview and breast milk immunology. Acta Paediatr. Jpn. 36:557-561. https://doi.org/10.1111/j.1442-200X.1994 .tb03246.x.

Hazes, J. M. 1991. Pregnancy and its effect on the risk of developing rheumatoid arthritis. Ann. Rheum. Dis. 50:71-72. https://doi.org/ 10.1136/ard.50.2.71.

Karataeva, N. A., V. N. Buneva, and G. A. Nevinsky. 2006b. Polysaccharide kinase activity of human milk IgG antibodies. Biochemistry (Mosc.) 71:1207-1221. https://doi.org/10.1134/ S000629790611006X.

Karataeva, N. A., D. Gorbunov, I. V. Prokudin, V. N. Buneva, A. A. Kulminskaya, K. N. Neustroev, and G. A. Nevinsky. 2006a. Human milk antibodies with polysaccharide kinase activity. Immunol. Lett. 103:58-67. https://doi.org/10.1016/j.imlet.2005.10.009.

Kazakov, V. I., V. M. Bozhkov, V. A. Linde, M. A. Repina, and V. M. Mikhailov. 1995. Extracellular DNA in the blood of pregnant women. Tsitologiia 37:232-236.

Keinan, E., ed. 2005. Catalytic Antibodies. Wiley-VCH Verlag GmbH and Co. KgaA, Weinheim, Germany.

Kit, Y. Ya., D. V. Semenov, and G. A. Nevinsky. 1996. Phosphorylation of different human milk proteins by human catalytic secretory immunoglobulin A. Biochem. Mol. Biol. Int. 39:521-527. https:// doi.org/10.1080/15216549600201571.

Matsuyama, H., and H. I. Suzuki. 2019. Systems and synthetic microRNA biology: From biogenesis to disease pathogenesis. Int. J. Mol. Sci. 21:132. https://doi.org/10.3390/ijms21010132.

Melnik, B. C., and G. Schmitz. 2017. MicroRNAs: Milk's epigenetic regulators. Best Pract. Res. Clin. Endocrinol. Metab. 31:427-442. https://doi.org/10.1016/j.beem.2017.10.003.

Mestecky, J., M. W. Russell, S. Jackson, and T. A. Brown. 1986. The human IgA system: A reassessment. Clin. Immunol. Immunopathol. 40:105-114. https://doi.org/10.1016/0090-1229(86)90073 -5 .

Miller, B. H., and C. Wahlestedt. 2010. MicroRNA dysregulation in psychiatric disease. Brain Res. 1338:89-99. https://doi.org/10 $.1016 /$ j.brainres.2010.03.035.

Murai, K., G. Sun, P. Ye, E. Tian, S. Yang, Q. Cui, G. Sun, D. Trinh, O. Sun, T. Hong, Z. Wen, M. Kalkum, A. D. Riggs, H. Song,
G. Ming, and Y. Shi. 2016. The TLX-miR-219 cascade regulates neural stem cell proliferation in neurodevelopment and schizophrenia iPSC model. Nat. Commun. 7:10965. https://doi.org/10.1038/ ncomms10965.

Nevinsky, G. A. 2010. Natural catalytic antibodies in norm and in autoimmune diseases. Pages 1-107 in Autoimmune Diseases: Symptoms, Diagnosis and Treatment. K. J. Brenner, ed. Nova Science Publishers Inc., New York, NY.

Nevinsky, G. A. 2011. Natural catalytic antibodies in norm and in HIV-infected patients. Pages 151-192 in Understanding HIV/ AIDS Management and Care-Pandemic Approaches the 21st Century. F. H. Kasenga, ed. InTech, Rijeka, Croatia.

Nevinsky, G. A. 2016. Autoimmune processes in multiple sclerosis: production of harmful catalytic antibodies associated with significant changes in the hematopoietic stem cell differentiation and proliferation. Pages 100-147 in Multiple Sclerosis. A. ConzalezQuevedo, ed. InTech, Rijeka, Croatia.

Nevinsky, G. A. 2017. Catalytic antibodies in norm and systemic lupus erythematosus. Pages 41-101 in Lupus. W. A. Khan, ed. InTech, Rijeka, Croatia.

Nevinsky, G. A., and V. N. Buneva. 2003. Catalytic antibodies in healthy humans and patients with autoimmune and viral diseases. J. Cell. Mol. Med. 7:265-276. https://doi.org/10.1111/j.1582-4934 .2003.tb00227.x.

Nevinsky, G. A., and V. N. Buneva. 2005. Natural catalytic antibodies-Abzymes. Pages 505-569 in Catalytic Antibodies. E. Keinan, ed. VCH-Wiley Press, Weinheim, Germany.

Nevinsky, G. A., T. G. Kanyshkova, D. V. Semenov, A. V. Vlassov, A. V. Gal'vita, and V. N. Buneva. 2000. Secretory immunoglobulin A from healthy human mothers' milk catalyzes nucleic acid hydrolysis. Appl. Biochem. Biotechnol. 83:115-129. https://doi.org/10 .1385/ABAB:83:1-3:115.

Nevinsky, G. A., Y. Kit, D. V. Semenov, D. Khlimankov, and V. N. Buneva. 1998. Secretory immunoglobulin A from human milk catalyses milk protein phosphorylation. Appl. Biochem. Biotechnol. 75:77-91. https://doi.org/10.1007/BF02787710.

Odintsova, E. S., V. N. Buneva, and G. A. Nevinsky. 2005. Caseinhydrolyzing activity of sIgA antibodies from human milk. J. Mol. Recognit. 18:413-421. https://doi.org/10.1002/jmr.743.

Paul, S., D. J. Volle, C. M. Beach, D. R. Johnson, M. J. Powell, and R. J. Massey. 1989. Catalytic hydrolysis of vasoactive intestinal peptide by human autoantibody. Science 244:1158-1162. https:// doi.org/10.1126/science.2727702.

Rechtman, D. J., B. Ferry, M. L. Lee, and H. Chapel. 2002. Immunoglobulin A (IgA) content of human breast milk over time. Int. J. Infect. Dis. 6(S3):S58. https://doi.org/10.1016/S1201 -9712(02)90302-4.

Savel'ev, A. N., T. G. Kanyshkova, A. A. Kulminskaya, V. N. Buneva, E. V. Eneyskaya, M. V. Filatov, G. A. Nevinsky, and K. N. Neustroev. 2001. Amylolytic activity of IgG and sIgA immunoglobulins from human milk. Clin. Chim. Acta 314:141-152. https://doi.org/ 10.1016/S0009-8981(01)00691-X.

Semenov, D. V., T. G. Kanyshkova, N. A. Karotaeva, M. A. Krasnorutskii, I. A. Kuznetsova, V. N. Buneva, and G. A. Nevinsky. 2004. Catalytic nucleotide-hydrolyzing antibodies in milk and serum of clinically healthy human mothers. Med. Sci. Monit. 10:BR23-BR33.

Tanaka, A., K. Lindor, A. Ansari, and M. E. Gershwin. 2000. Fetal microchimerisms in the mother: Immunologic implications. Liver Transpl. 6:138-143. https://doi.org/10.1002/lt.500060225.

Vlasov, A. V., A. G. Baranovskii, T. G. Kanyshkova, A. V. Prints, V. G. Zabara, V. A. Naumov, A. A. Breusov, R. Giege, V. Buneva, and G. A. Nevinskii. 1998. Substrate specificity of serum DNAand RNA-hydrolyzing antibodies of patients with polyarthritis and autoimmune thyroiditis. Mol. Biol. (Mosk.) 32:559-569.

Vlasov, A. V., M. Helm, V. A. Naumov, A. A. Breusov, V. N. Buneva, C. Florentz, R. Giege, and G. A. Nevinskii. 1999. Features of tRNA hydrolysis by autoantibodies from blood serum of patients with certain autoimmune and virus diseases. Mol. Biol. (Mosk.) 33:866-872. 
Vlassov, A., C. Florentz, M. Helm, V. Naumov, V. Buneva, G. Nevinsky, and R. Giegé. 1998. Characterization and selectivity of catalytic antibodies from human serum with RNase activity. Nucleic Acids Res. 26:5243-5250. https://doi.org/10.1093/nar/26.23.5243.

Vlassov, A. V., M. Helm, C. Florentz, V. Naumov, A. A. Breusov, V. N. Buneva, R. Giege, and G. A. Nevinsky. 1999. Variability of substrate specificity of serum antibodies obtained from patients with different autoimmune and viral diseases in reaction of tRNA hydrolysis. Russ. J. Immunol. 4:25-32.

Watanabe-Fukunaga, R., C. I. Brannan, N. G. Copeland, N. A. Jenkins, and S. Nagata. 1992. Lymphoproliferation disorder in mice explained by defects in Fas antigen that mediates apoptosis. Nature 356:314-317. https://doi.org/10.1038/356314a0.

\section{ORCIDS}

Evgeny A. Ermakov @ https://orcid.org/0000-0002-1084-6419

Sergey E. Sedykh (ㄴ) https://orcid.org/0000-0003-0882-8171

Valentina N. Buneva @ https://orcid.org/0000-0003-2556-979X

Georgy A. Nevinsky @ https://orcid.org/0000-0002-4988-8923 